\title{
Airway obstruction caused by pharyngolaryngeal swelling after intraoral removal of a submandibular gland stone
}

This article was published in the following Dove Press journal:

Therapeutics and Clinical Risk Management

\author{
Satomi Sugiyama \\ Toshinori Iwai \\ Nobuhide Ohashi \\ Senri Oguri \\ Makoto Hirota \\ Kenji Mitsudo
}

Department of Oral and Maxillofacial Surgery/Orthodontics, Yokohama City University Hospital, Yokohama, Japan
Correspondence: Toshinori Iwai

Yokohama City University Hospital,

3-9 Fukuura, Kanazawa-ku, Yokohama,

Kanagawa 2360004 , Japan

Tel +8I 457872659

Fax +8I 457858438

Email iwail04oams@yahoo.co.jp

\begin{abstract}
Intraoral removal of a submandibular gland stone is less invasive than submandibulectomy, with no life-threatening airway complications reported until now. We report a case involving airway obstruction caused by pharyngolaryngeal swelling after intraoral removal of a submandibular gland stone. A 31-year-old man with a left submandibular gland stone underwent intraoral removal of the stone under general anesthesia and was discharged 1 day after surgery. That night, he was transported back to our hospital by ambulance for dyspnea. Because computed tomography showed pharyngolaryngeal swelling, he was intubated and managed by a ventilator. Four days later, the pharyngolaryngeal swelling had mostly resolved and he was extubated and discharged. Surgeons should be vigilant of the potential risk of airway complications following an intraoral approach for submandibular gland stone removal.

Keywords: airway obstruction, intraoral removal, sialolithiasis, submandibular gland stone, complication
\end{abstract}

\section{Introduction}

Salivary gland stones are commonly located in the submandibular gland, ${ }^{1,2}$ with around $50 \%$ of such stones found in the proximal/hilar region. ${ }^{3}$ Small stones in this region can now be removed with minimal invasiveness by sialendoscopy; ${ }^{4-6}$ large stones are removed through an intraoral incision. ${ }^{6-8}$ Although intraoral removal of proximal/hilar or intraglandular stones is technically difficult, intraoral removal has several advantages over submandibular sialoadenectomy, including no visible scarring, no facial nerve injury, shorter operation time, and better gland function. ${ }^{1,9}$ The complications reported for intraoral removal are mainly temporary lingual nerve paralysis, postoperative infection or bleeding, development of traumatic ranula, and ductal stricture. No life-threatening airway complications have been reported to date. We report here such a case, involving airway obstruction caused by pharyngolaryngeal swelling after intraoral removal of a submandibular gland stone.

\section{Case report}

A 31-year-old man with no allergies attended another otolaryngology clinic for a left submandibular swelling and was diagnosed with submandibular gland stone. Intraoral removal of the stone was attempted at under local anesthesia, but the stone migrated deeply and could not be removed. The stone remained in its deep location over 4 months of follow-up. Therefore, he was referred to our department for sialendoscopy. Upon presentation to us, he had no past medical history except for obesity 

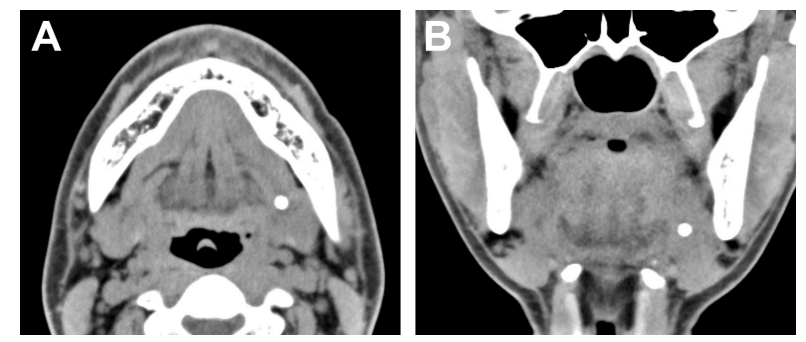

Figure I Preoperative CT.

Note: (A) Axial image and (B) coronal image.

Abbreviation: CT, computed tomography.

(body mass index: 26). Computed tomography (CT) showed a stone $(4.4 \times 4.0 \times 3.9 \mathrm{~mm})$ located in hilar region of left submandibular gland (Figure 1). We performed outpatient sialendoscopy of the palpable stone under local anesthesia, but the sialendoscope could not reach the stone due to a ductal stricture. Therefore, several weeks later, we performed intraoral removal of the stone under general anesthesia. After retraction of the tongue using a tongue retractor, a 3 -cm mucosal incision was made on the lingual aspect of the retromolar region. The exposed sublingual gland was retracted laterally, and Wharton's duct and the lingual nerve were identified. After careful dissection along Wharton's duct to the hilum of the submandibular gland, the submandibular gland was raised with extraoral finger pressure and the medial aspect of the submandibular gland was exposed. An incision was made on the hilum after palpation of the stone, and the stone was removed. The hilum was sutured to the oral mucosa, and an orifice was made for salivary flow. Operation time was 28 minutes and bleeding was negligible. The patient was discharged 1 day after surgery without complications; he had no lingual nerve paralysis nor dyspnea. However, that night he experienced dyspnea when supine and was transported by ambulance back to our hospital. The left submandibular region was moderately swollen, the oral floor was slightly swollen, and there was no bleeding from the wound. CT showed pharyngolaryngeal edema from the left submandibular gland to the epiglottis (Figure 2). The fiberscopic
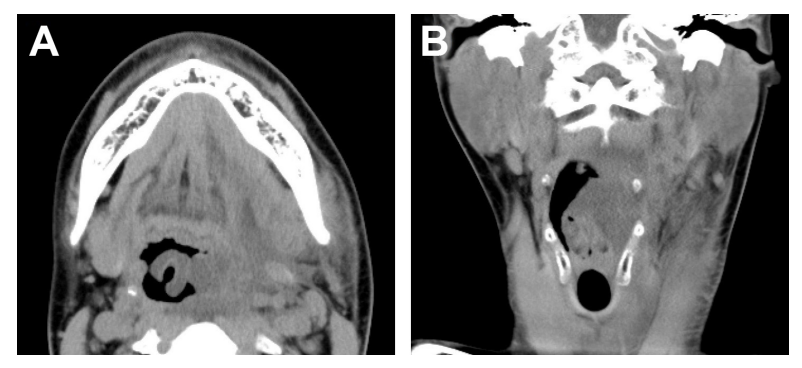

Figure 2 CT before tracheal intubation showing pharyngolaryngeal edema from the left submandibular gland to the epiglottis.

Note: (A) Axial image and (B) coronal image.

Abbreviation: CT, computed tomography.

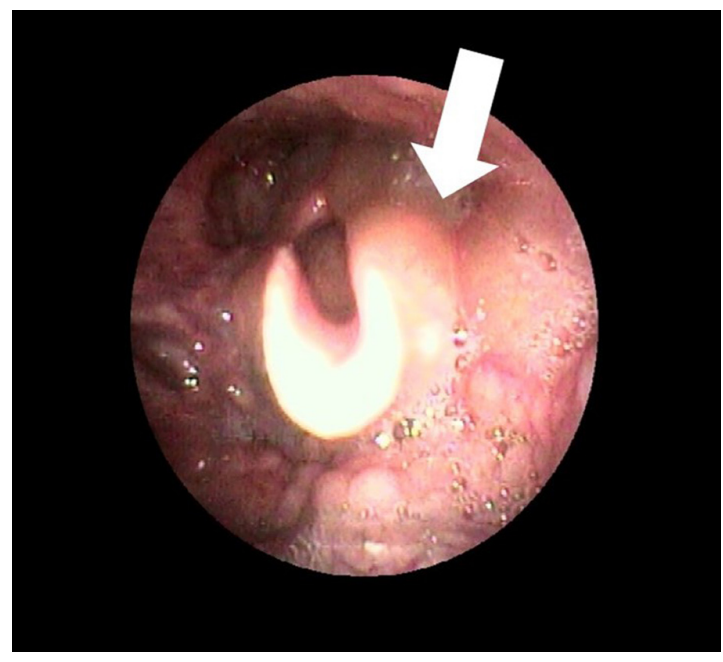

Figure 3 Fiberscopic image showing edema (arrow) from the epiglottis to the left lateral arytenoid cartilage.

image showed edematous swelling from the epiglottis to the left lateral arytenoid cartilage (Figure 3). After discussion with anesthesiologists and otolaryngologists, we intubated and mechanically ventilated the patient and admitted him to the intensive care unit. He was given antibiotics and steroids. Although the wound was released by suture removal after intubation, there was no bleeding or hematoma. Follow-up $\mathrm{CT}$ and fiberoptic nasal endoscopy 4 days later showed that the pharyngolaryngeal swelling had mostly resolved, and he was extubated and discharged.

\section{Discussion}

Proximal/hilar submandibular gland stones are traditionally treated with sialoadenectomy, with potential risks of facial nerve injury and visible scarring. Therefore, a minimally invasive approach has been favored in recent years, with the application of intraoral removal, endoscopic removal, or a combination of both for gland preservation. ${ }^{1-9}$ Although small stones in this region can be removed by sialendoscopy, intraoral removal of large proximal/hilar or intraglandular stones is challenging because the surgical field is limited., ${ }^{2,9}$ However, intraoral removal of deep submandibular gland stones has several advantages over submandibular sialoadenectomy, including shorter operation time and better gland function. ${ }^{1,9}$ To overcome the technical difficulties, we have developed a novel tongue retractor. ${ }^{8}$

The potential complications of intraoral removal of submandibular gland stones are lingual nerve paralysis, ranula and ductal stenosis, and edema of soft tissues. Although swelling of the oral floor after intraoral removal is observed in $75 \%-100 \%$ cases $^{6}{ }^{6}$ to our knowledge, there are no previous reports of life-threatening airway complications after 
conventional intraoral stone removal. However, airway obstruction was reported as a complication of sialendoscopy, which is a minimally invasive procedure. ${ }^{5}$ In that case, the airway complication was caused by extraductal leaking of saline injected to spread the duct after the duct perforation.

Our patient was obese (with a body mass index $>25$ ) and snored during sleep. A retrospective review of preoperative CT images revealed ipsilateral tonsillar hypertrophy. Consequently, he had high risk of postoperative airway complication. Based on our experience in this case, we now routinely evaluate pharyngolaryngeal swelling on CT images 1 day after simultaneous intraoral removal of bilateral proximal/ hilar submandibular gland stones. We commonly see pharyngeal edema that does not involve the larynx, where the soft tissue swelling is likely caused by release of the suprahyoid muscles from the medial aspect of the submandibular gland. Postoperative pharyngeal pain during swallowing may be due to this pharyngeal swelling.

\section{Conclusion}

Surgeons should be vigilant of the potential risk of airway complications following an intraoral approach for submandibular gland stone removal. We recommend close observation of patients with tonsillar hypertrophy, obstructive sleep apnea, obesity, or bilateral submandibular gland stones as these may be risk factors for airway complications.

\section{Ethics statement}

Written informed consent was obtained from the patient, and the review and approval of the institutional review board was not required. The patient agreed for his photos, images, and information to be applied to this research and allowed them to be published in this journal.

\section{Disclosure}

The authors report no conflicts of interest in this work.

\section{References}

1. Combes J, Karavidas K, McGurk M. Intraoral removal of proximal submandibular stones - an alternative to sialadenectomy? Int J Oral Maxillofac Surg. 2009;38(8):813-816.

2. Roh JL, Park CI. Transoral removal of submandibular hilar stone and sialodochoplasty. Otolaryngol Head Neck Surg. 2008;139(2):235-239.

3. Sigismund PE, Zenk J, Koch M, Schapher M, Rudes M, Iro H. Nearly 3,000 salivary stones: some clinical and epidemiologic aspects. Laryngoscope. 2015;125(8):1879-1882.

4. Su CH, Tseng H, Lee KS, Tseng TM, Hung SH. Experiences in the treatment of obstructive sialoadenitis with sialendoscopy. B-ENT. 2016;12(3):199-206

5. Baptista P, Gimeno CV, Salvinelli F, Rinaldi V, Casale M. Acute upper airway obstruction caused by massive oedema of the tongue: unusual complication of sialoendoscopy. J Laryngol Otol. 2009;123(12): 1402-1403.

6. Capaccio P, Clemente IA, McGurk M, Bossi A, Pignataro L. Transoral removal of hiloparenchymal submandibular calculi: a long-term clinical experience. Eur Arch Otorhinolaryngol. 2011;268(7):1081-1086.

7. McGurk M. Surgical release of a stone from the hilum of the submandibular gland: a technique note. Int J Oral Maxillofac Surg. 2005;34(2): 208-210.

8. Oguri S, Iwai T, Ueda J, Tohnai I. Use of a novel tongue retractor for intraoral removal of proximal/hilar submandibular gland stone. J Oral Maxillofac Surg Med Pathol. 2017;29(4):306-308.

9. Eun YG, Chung DH, Kwon KH. Advantages of intraoral removal over submandibular gland resection for proximal submandibular stones: a prospective randomized study. Laryngoscope. 2010;120(11):2189-2192.
Therapeutics and Clinical Risk Management

\section{Publish your work in this journal}

Therapeutics and Clinical Risk Management is an international, peerreviewed journal of clinical therapeutics and risk management, focusing on concise rapid reporting of clinical studies in all therapeutic areas, outcomes, safety, and programs for the effective, safe, and sustained use of medicines. This journal is indexed on PubMed Central, CAS

\section{Dovepress}

EMBase, Scopus and the Elsevier Bibliographic databases. The manuscript management system is completely online and includes a very quick and fair peer-review system, which is all easy to use. Visit http://www.dovepress.com/testimonials.php to read real quotes from published authors. 